\title{
System of greening of urban spaces and its role in optimization of the micro- and bioclimate environment
}

\author{
Adham Giyasov ${ }^{1, *}$ \\ ${ }^{1}$ Moscow State University of Civil Engineering, 129337, 26, Yaroslavskoe shosse, Moscow, Russian \\ Federation
}

\begin{abstract}
The article is devoted to the issue of sustainable development of green areas of the urbanized environment. The main problems of the functional filling of the open spaces of the urban territory with a green structure in the natural framework system and the impact of landscaping on the ecological environment are considered. The role of the urban greening system in multi-storey buildings with the aim of optimizing the micro- and bioclimatic environment is studied. Examples of using landscaping techniques as an important component of the natural landscape as means to compensate for anthropogenic impact are given. Real data have been obtained on the microclimatic and bioclimatic effectiveness of landscaping of various sizes, which determine the planning structure of the urban area with the appropriate techniques and principles of landscaping in the field of dendrology of cities of southern latitude. Variants of intensive landscaping of the urban area are proposed.
\end{abstract}

\section{Introduction}

The creation of a favorable ecologically full and harmonious architectural and landscape living environment in the conditions of multi-storey mass development that meets sanitary, hygienic, functional and aesthetic and artistic requirements involves the improvement and landscaping of the entire city territory.

Gardening, being an important area in the biosphere compatibility of cities, holds a special place in the urban organism. It contributes to the successful functioning of its individual elements, while at the same time, being one of the most significant functional and spatial systems of the city, largely determines the ecological quality of the urban environment.

The city's landscaping system is considered to be rationally placed on its territory green spaces of general, limited use and special purpose, combined into a network of natural and artificial green channels connecting all elements of urban landscaping with green areas and open spaces surrounding the city.

Rationing of green spaces of the city is carried out depending on its purpose, size of the territory, building density, climatic conditions, the existing architectural and planning decisions of the city.

The green space system to a large extent determines the architectural and planning structure of the city and buildings. An example is the well-known system of the so-called

* Corresponding author: adham52@mail.ru 
"green wedges" in Moscow, the "green diameter" in Minsk, which determined the uniqueness and character of the planning structure of these cities; the old satellite cities of London, built on the basis of the "garden city" principle, have a completely different planning structure than the new cities of England - Hook and Cumbernauld, built on the basis of the "garden city" principle. A number of practical solutions of the "green designer" are also noted as the "forest city" in China, the "forest on the roofs" in Beirut, the "green roof" in Astana, the "vertical gardens" in Russia, the "futuristic smart city" in Paris.

Currently, there are more than 30 national rating systems for rating "green" construction worldwide: in Australia - Green Star; Brazil - AQUA; UK - BREEAM; Finland - PromisE; France - HQE; Germany - DGNB; Hong Kong - HK BREAM; India - GRIHA; Italy - Green Building Counsil Italia; Spain - VERDE; Canada - LEED Canada; China - GBAS; Malaysia GBI Malaysia; Netherlands - BREEAM Netherlands; USA - LEED; Switzerland - Minergie; South Africa - Green Star SA; Japan - CASBEE.

To date, the BREEAM rating system has become the most widely used worldwide - the first environmental assessment method, the Building Research Establishment Environmental Assessment Method (BREEAM).

Application of international "green standards" in the construction field to develop and build bio-positive buildings with plant integration in the building structure (BoscoVerticale residential complex in Italy and Minton in Singapore, House in Denmark, green floors of the EDITT Tower in Australia, Diadema Club House in St. Petersburg, Russia) allowed accumulating experience and demonstrate solutions to aesthetic, energy and environmental problems.

In this regard, the National Urban Doctrine of the Russian Federation and the Sustainable Development Strategy pay special attention to the maximum conservation and rational use of natural resources while creating a harmonious and comfortable environment for humans [1-4].

In the future, "green standards" are aimed at a difficult task, i.e. consideration of the problems of environmental saving from the beginning to the end of the life cycle of buildings, structural parts of cities or their full utilization.

"Green" infrastructure is one of the theses of sustainable development of the urban environment, to which a number of foreign studies have been devoted [5-8].

A significant amount of domestic and foreign studies has been devoted to the study and implementation of this concept in urban development programs of different cities [9-14].

In the CIS countries, the issue of greening urban areas is also being actively studied, methods for introducing elements of "green" infrastructure in the daily fabric of the city are analyzed and developed.

Green spaces have a beneficial effect on the air environment of the surrounding area. This property of greenery has been noticed for a long time, which is noted in the works of many authors, but there is no consensus on this issue. Some authors believe that only large green areas with an area of several hectares affect the adjacent territory [15-18]. Others argue that small groups of greenery, characteristic of intra-quarter landscaping, also have a beneficial effect on the surrounding area [19,20].

For cities located in the southern latitudes, the problem of optimizing the radiant energy of the sun, temperature-radiation, thermal, humidity and wind regimes is of particular importance.

The degree of influence of green spaces on the temperature-radiation and humidity conditions depends on the characteristics of different tree species: growth, density and diameter of the crown, leaf structure and shape, height of the stem, which were studied in the following works .

The influence of green spaces on the wind regime is great. The mechanism of influence is that moving air masses, meeting an obstacle in the form of a green mass, are condensed at 
the edge and, depending on the density of plantings, partially penetrate inside (30-40\%) and partially flow around it from above. On the leeward side, at a considerable distance from it (up to 40 heights), on the opposite side in the open territory, the wind speed is lower than the original.

In order to identify the reclamation effect of the system of green structures in the microand bioclimate of adjacent territories, meteorological environmental factors in and around green spaces were studied depending on the size and layout of green areas in the climatic conditions of southern latitudes.

\section{Methods}

The degree of influence of green spaces on the factors of micro- and bioclimate, which is especially important for cities located at equatorial latitudes, depends on the characteristics of different tree species: growth, diameter and density of the crown, transparency of the crown and the degree of shade, structure and shape of the leaf, the size and layout of the green massif and plantings.

In order to identify the effectiveness of green spaces and woodlands in the formation of important environmental factors, such as temperature and humidity, wind, insolation of urban areas, comprehensive field, laboratory and model studies, and computer studies of meteorological factors were performed on freestanding green planting groups and above woodlands of different sizes and layouts. Graphical and analytical calculations of light and shade from green structures were also made.

\section{Results}

In order to universally improve the radiation, thermal, temperature, humidity, and wind background of the urban area in the southern region, it is recommended to focus on a system of continuous uniformly distributed distribution of green spaces and differentiation of the area occupied by them in accordance with the functional purpose and degree of microclimatic and bioclimatic efficiency, as well as the effectiveness of several other environmental factors.

When organizing urban landscaping systems, it becomes necessary to provide for the protection of the latter from solar and thermal radiation of all kinds, to intensify the ventilation of the territory and to evaluate the area of green spaces, taking into account the possible local reclamation effect, as well as their impact on the surrounding territory.

As a result of the studies, a number of dependencies were obtained on the reclamation effect of green spaces, some of which were given in a previous work [19].

The total landscaping area of cities, including all types of green spaces and their effectiveness in the temperature and humidity conditions of the territory depending on the percentage of landscaping, are presented in Fig. 1, which are recommended for use in the planning of landscaped areas when developing a master plan, drawing up a dendrological plan and a plan of urban development planning.

The area of green spaces, taking into account the possible local temperature effect, as well as their influence on the surrounding territory, is shown in Fig. 2.

It should be noted that the minimum bioclimatic significant decrease in air temperature is observed in green spaces with an area of 1 ha. An additional decrease in air temperature by a value of practical importance $-0.5^{\circ} \mathrm{C}$ is observed with an area of 4-5 ha, then 10 ha.

In massifs larger than 20 ha, an additional decrease in air temperature by $0.5{ }^{\circ} \mathrm{C}$ is noticeably manifested when its area is increased by 10 ha or more.

It has been established that separate massifs of green spaces should be provided for in a compact form, approaching a square, a circle, an isosceles triangle. At the same time, it is recommended to 
provide for density of planting of $0.5-0.7$ in cities with low air mobility in the evening and night hours and 0.8-0.9 at normal wind speeds.

a

$$
{ }^{\mathrm{o}} \mathrm{C}
$$

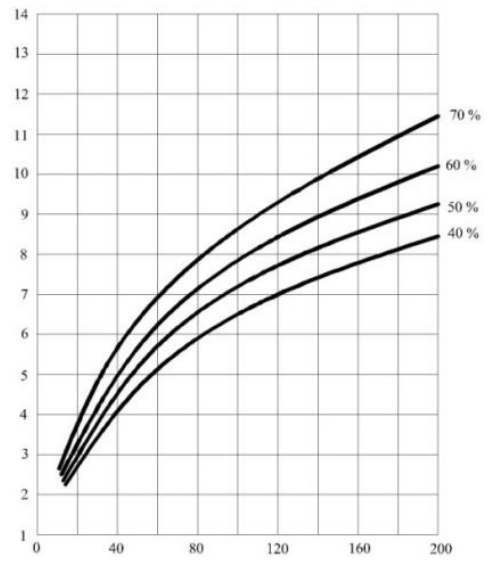

\section{$\mathrm{b}$}

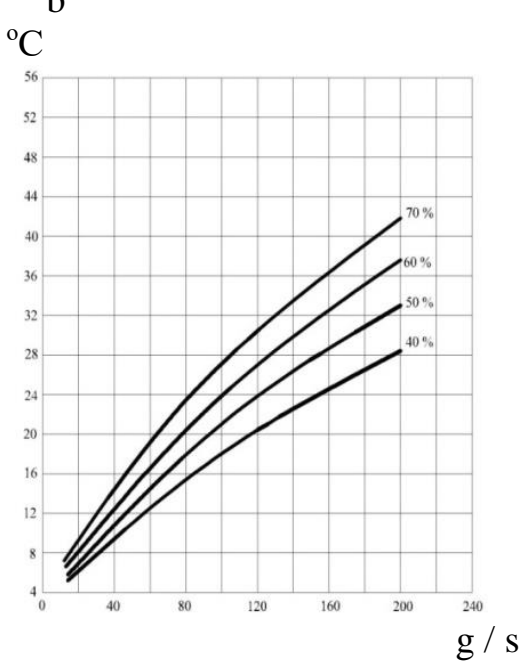

Fig. 1. Change in temperature (a) and humidity (b) of the urban area depending on the percentage of landscaping and the amount of evaporated moisture from 1 ha of territory

In the conditions of the city, the thermoregulatory significance of large green areas, such as a city park, is manifested in the fact that they contribute to the natural thermal ventilation of the territory, creating local breezes even with a common calm. The graphs shown in Fig. 3 show the air flow velocities (up to $5 \mathrm{~m} / \mathrm{s}$ ) caused by green spaces in urban areas in a calm atmosphere with a temperature difference between the green space and the adjacent territory without plants.

Biological processes in plants cause significant cooling of the air, which goes down and displaces the lower layer of warmer air. Due to the difference (up to $10-12{ }^{\circ} \mathrm{C}$ ) of the air temperature between the green and open or built-up territory, the air masses move horizontally at a distance of $1 \mathrm{~km}$ from the green areas to the environment at a speed of 4.5 $5 \mathrm{~m} / \mathrm{s}$, i.e. the air of open areas rises upward, and colder air flows from its green space into its place, forming local winds of thermal origin.

Vegetation, having a large evaporative ability, has a noticeable effect on the temperature and humidity of the air, causing a positive heat sensation of a person. In large green spaces, on hot days, the temperature, compared to the adjacent built-up area, decreases by $4-6{ }^{\circ} \mathrm{C}$, and air humidity rises to $18-20 \%$, reaching comfortable values.

For quantitative estimates of the thermal state of a person, these microclimate factors of the city are insufficient. In this regard, to assess the thermal effects of anthropogenic factors in the urban environment, a criterion was adopted, expressed in quantitative measure and reflecting the physiological reactions of the body, which determines the indicator of heat load in the form of moisture loss on the evaporation of $\mathrm{FE}, \mathrm{g} / \mathrm{h}$.

The heat load per person in the form of moisture loss due to evaporation of $\mathrm{FE}, \mathrm{g} / \mathrm{h}$ in a typical greened and landscaped house territory, taking into account the insolation condition, is shown in Fig. 4.

A person, being in the real conditions of the adjoining territories of the urban environment, is exposed to many local factors that have a total thermal effect on the body. At the same time, the role of gardening is significant, contributing to a decrease in $\mathrm{FE}=800$ $\mathrm{g} / \mathrm{h}$ from a particularly unfavorable level in a house area without plants, to a favorable level 
$\mathrm{FE}=200 \mathrm{~g} / \mathrm{h}$ in a green house area during the overheating hours of the day with a temperature difference between adjacent inter-house territories of $12-13{ }^{\circ} \mathrm{C}$.

a

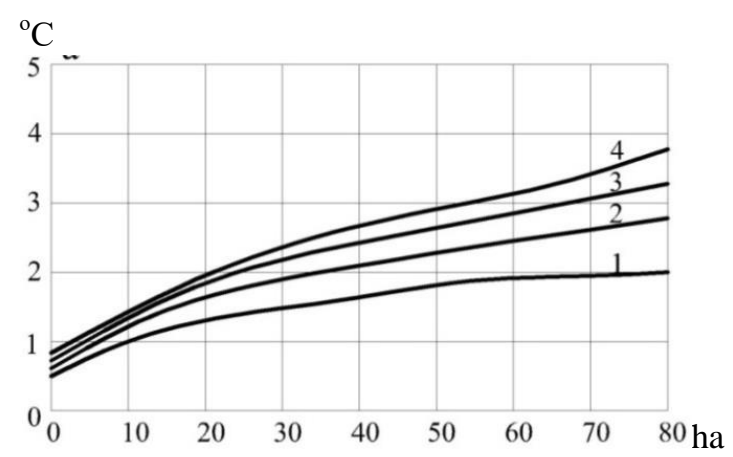

b

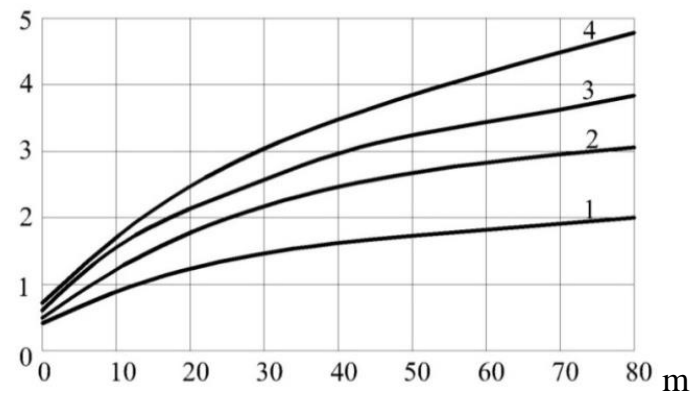

$\mathrm{c}$

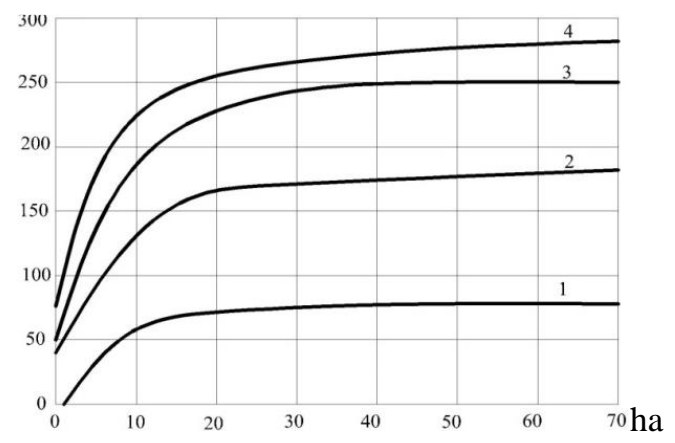

Fig. 2. Change in temperature (a) and humidity (b) in air in green spaces and the radius of their influence on the adjacent territory (c) depending on small (1), medium (2), large (3.4) amount of evaporated moisture 


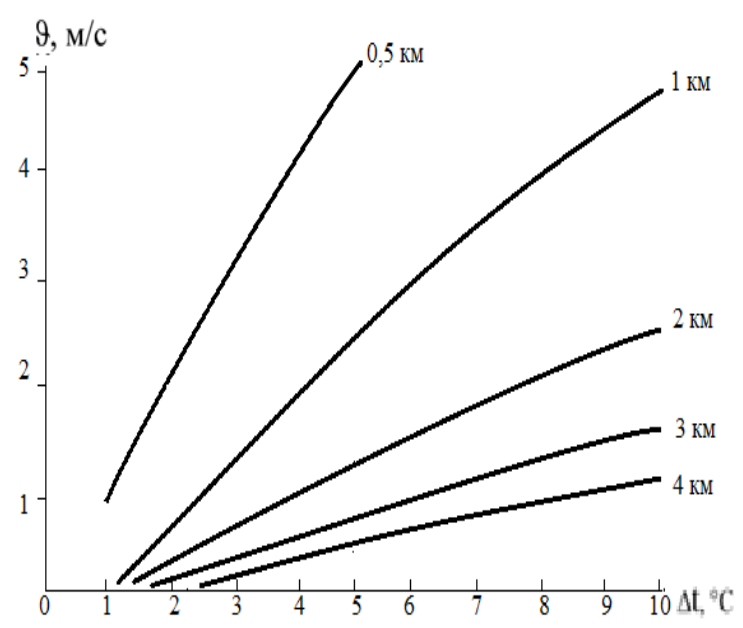

Fig. 3. Local downstream winds

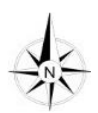

a

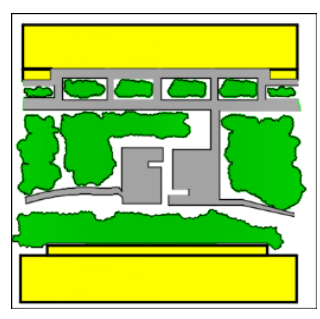

c

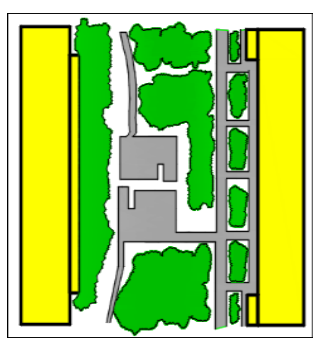

b

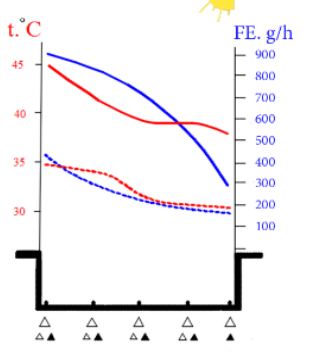

d

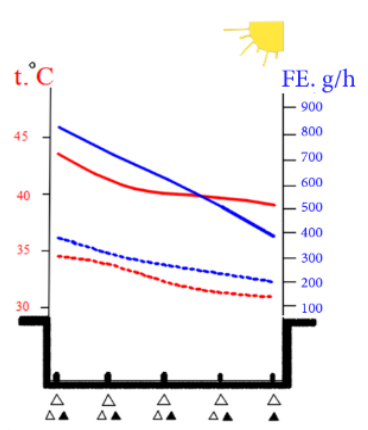

$\Delta$ - point in the shade; $\boldsymbol{\Delta}$-point is insolated; $\Delta \boldsymbol{\Delta}$-point is partially insolated, straight and dashed lines - indicators of house adjoining space with and without plants

Fig. 4. Micro- and bioclimatic assessment of adjacent green areas of latitudinal and meridional orientation: a, c - location options for structure-forming plants, taking into account their shading ability, b, d - micro- and bioclimatic sections of the adjacent territory. July. 


\section{Discussions}

The positive property of greenery as a factor forming the microclimate and bioclimate does not require unlimited use of greenery, but it should be used systemically.

Studies have shown that landscaping with vegetation of medium or low height is best suited as a screen at high wind speeds in windy cities. Large-sized large-crowned tree plantations between the city and its suburbs and within the city promote the exchange of air and protect against much solar radiation to a much greater extent.

In cities with a calm climate, the combination of woodlands or groups of green spaces with the adjacent territory without plants, with thermal and temperature contrast of the environment between them, determines the formation of local breeze winds.

Wood plantings with a developed and high, open and dense deciduous crown, high boles reduce radiation and convection temperatures, increase air humidity, improve the ventilation of urban areas in the summer, increase the positive impact of green structures on environmental factors as a whole by 1.3-1.5 times higher.

\section{Conclusions}

The microclimatic and bioclimatic background of urban areas as a whole and of individual buildings depends on the area of the territory, the structure of landscaping and the radius of its influence, which is important to take into account when planning and designing cities and settlements.

The obtained evidence and dependencies on the efficiency of green spaces in assessing important environmental factors of the microclimate and bioclimate environment predetermined a number of provisions on the formation of the planning structure of urban development with the appropriate techniques and principles of green construction.

\section{Recommendations}

To protect cities from hot summers and cold winter winds, it is recommended to provide protective green or evergreen lines from the side of their influence. The sizes of green lines, which provide protection from adverse winds and mitigate the temperature regime of the city as a whole, are recommended to be taken within $0.9-1.0$ of the city area. The width of the green lines must be at least $100 \mathrm{~m}$.

In the cities of the southern equatorial region, for landscaping territories used during daylight hours, it is recommended to use tall large-crowned deciduous trees with a plant density of $0.8-1.0$, which can obscure useful areas and reduce the intensity of solar radiation to $95-98 \%$, as well as protect from overheating the walls of architectural and engineering objects, reducing the heating of bridges and walls of buildings.

In cities located on the border with the desert, trees, shrubs and lawn grasses should be maximally landscaped. To protect settlements from sand drifts, it is necessary to envisage a series of landscaping works with creating at least $1 \mathrm{~km}$ wide zones around cities or settlements, preserving the existing vegetation cover around cities at a distance of at least 2 $\mathrm{km}$, as well as periodically renewing vegetation cover by air sowing.

The volumetric-spatial composition of the planting of boulevards, alleys, pedestrian footpaths should be built primarily on a linear-stripe combination of three types of spaces: closed, open, half-open. Visual disclosure can be achieved by a clear orientation of the alleys to the object. To do this, it is appropriate to use the following types of vegetation - trees with a clear crown shape: pyramidal, perimeter, etc. Paths up to $6 \mathrm{~m}$ wide should be landscaped with double-row planting of broad-leaved deciduous trees. It is proposed to create two dense 
shading zones on the sides of the alley for daytime stay and accompanying them with a stall insolated only in the evening, which is only a visually developed zone during the day.

The selection of gardening techniques for pedestrian connections should be made depending on their width and aero-helio-thermal orientation. Along the pedestrian paths with a width of up to $1.5-2.2 \mathrm{~m}$ in all orientations, it is recommended to use plantings of broadcrown hardwoods of the first and second sizes with a dense crown.

For shading plantings of pedestrian alleys of more than $2.2 \mathrm{~m}$ of the meridional direction, it is advisable to symmetrically arrange in plan and height on their opposite sides of tree species of the first and second sizes with a dense crown of a pyramidal or oval shape in combination with П-shaped pergolas, screens twined with climbing plants. For shading plantings, pedestrian alleys with a width of more than $2.2 \mathrm{~m}$ in the latitudinal and diagonal directions, it is recommended that the plantations be arranged asymmetrically in plan and in height on opposite sides of the paths: from the S, SE, SW, it is advisable to use wide-crowned trees of the first, second sizes with a dense crown, from the N, NE, NW sides - planting trees of the third, fourth sizes with medium-density crowns in combination with $\Gamma$-shaped screens twined with climbing plants.

The composition of green spaces in the adjoining territories of residential yards should be a single whole with the landscaping system of the microdistrict. The total area of green areas of the most appropriate functional areas: around the house, relaxing and walking, active recreation in the balance should be $60-75 \%$.

Gardening techniques for residential courtyards must be differentiated depending on the orientation of the facades of residential buildings and the location of the entrances. Along the facades of residential buildings of E, SE, SW, W orientations, planting lines with a width of $8 \mathrm{~m}$ with three rows of tree plantings with dense crowns should be provided; trees of the first size with a narrow pyramidal crown shape should be placed in the first and second row from the walls of buildings, and wide-crowned trees of the first and second size in the third row.

On the side of facades oriented to N, NE, NW, S it is allowed to reduce the width of the house adjoining lines to $5 \mathrm{~m}$ with 1-2 rows of trees of the second, third sizes with medium density crowns. On the outer perimeter of tree plantings, it is advisable to provide for planting two rows of hedges from shrubs. To enrich the architectural and spatial composition of the existing buildings in ordinary plantings, alternating rocks with various crown shapes, foliage colors, etc., combined with the rhythm of volumes and proportions of buildings in the housing system can be found at regular intervals. Small landscaping areas have the necessary reclamation effect on the immediate environment, forming the so-called centers of coolness - an oasis. Therefore, small areas are recommended to be constantly expanded with additional plantings. The architectural and spatial organization of the green zone, in conjunction with the requirements of the micro- and bio-climate, should be built primarily on a sparse arrangement of dense groups. Zones of sparse planting types in residential buildings create isolation of houses and lines near houses from each other at the level of the first or second floors. At the same time, structure-forming plantations should be distributed according to the following elements of the territory: along pedestrian alleys and paths, facades of houses irradiated in the afternoon, decorative groups. These plantations form the main spatial composition of the plantings. The compositions should be provided for aeration and visual breaks. It is recommended to place trees and shrubs in the adjacent area so that they do not obscure the windows of the apartments and do not interfere with the ventilation of the buildings. The laconicism of the facades, which is characteristic for modern buildings, vertical landscaping, and a vertical garden like no other give picturesqueness to buildings and facades, serving as a screen on the path of prolonged insolation in the hot season and as a mean of access to irradiation of premises during the normalized period.

According to the functional purpose, the public area of the microdistrict is formed mainly by flat areas, here it is landscaping that creates the main volumetric and spatial scale of the 
composition. In this case, the most valuable ornamental species, a variety of related types of vegetation, including exotics, compositions of annual and perennial flowers, as well as a significant percentage of evergreens, can be used to preserve decorativeness in winter.

The specifics of the layout and composition of landscaped areas of the public zone of a group of residential buildings is determined by the relatively large sizes of its constituent elements (gaming, sports and other playgrounds) located mostly outside the radius of the microclimatic influence of the building. In this regard, the volume of green spaces plays a dominant role in the formation of its architectural and spatial composition and microclimatic and bioclimatic conditions. In the architectural and spatial solution of landscaped areas, one should strive for a greater saturation with the formative means of landscape architecture than in the adjoining territory, and actively introduce the most valuable hardwoods, evergreen species of vegetation with a quantitative predominance of several leading species. In order to highlight the compositional center of the zone - a place for adults and children to relax, it is recommended to create a system of visual landmarks such as fountains, pools, sculptures that stand out clearly against the background of vegetation; artificial microrelief; combinations of special decorative plants, emphasizing the completion of the alleys, their turns, intersections.

To shade sports and playgrounds, places of quiet rest along their inner perimeter from $\mathrm{S}$, SW, SE sides, it is necessary to plant wide-crowned trees of the first size with a dense crown, from $\mathrm{W}$ and $\mathrm{E}$ sides - to plant trees of the first size with a dense pyramidal crown and from NW, NE, N sides - trees of the third, fourth sizes with open crown. Small areas are recommended to be additionally landscaped with T-, L-, U-shaped screens twined with climbing plants. Sports and playgrounds adjacent to quiet areas should have soundproofing strips created from 3-5 rows of dense plantings of the first, second sizes with undergrowth shrub layer.

The starting point for developing the composition of the territory of microdistricts should be the placement of structure-forming plantations on the general plan taking into account the functional zones presented in the table.

Table 1. Recommended planting type ratios for various functional areas of the microdistrict residential area

\begin{tabular}{|l|c|c|c|}
\hline \multicolumn{1}{|c|}{ Type of planting } & $\begin{array}{c}\text { In pedestrian } \\
\text { roads and } \\
\text { alleys, } \%\end{array}$ & $\begin{array}{c}\text { In the local } \\
\text { area, } \%\end{array}$ & $\begin{array}{c}\text { In the public zone } \\
\text { of the } \\
\text { microdistrict, } \%\end{array}$ \\
\hline $\begin{array}{l}\text { Dense tree plantings with a } \\
\text { closed canopy of plantations } \\
\text { of 0.7-1.0 }\end{array}$ & $65-80$ & $50-65$ & $50-70$ \\
\hline $\begin{array}{l}\text { Sparse tree plantings with a canopy } \\
\text { of plantations 0.3 - 0.5 }\end{array}$ & $5-15$ & $15-30$ & $10-20$ \\
\hline $\begin{array}{l}\text { Open spaces covered with ground } \\
\text { cover vegetation: flowers, lawn }\end{array}$ & $20-30$ & $10-12$ & $5-15$ \\
\hline $\begin{array}{l}\text { Open spaces without vegetation: } \\
\text { paving, soil, ponds }\end{array}$ & $3-5$ & $5-10$ & $15-30$ \\
\hline
\end{tabular}

\section{Acknowledgements}

The work was carried out in accordance with the plan of the research work of the department on the problem "Function, construction, environment in the architecture of buildings and cities". 


\section{References}

1. The Urban Planning Code of the Russian Federation dated December 29 2004, 190-FZ (2018) URL: http: //www.consultant.ru/document/cons_doc_LAW_51040/

2. The National Urban Planning Doctrine of the Russian Federation, URL: http://www.sro-mrp.ru/docs/drugoe/grad-doktrina.pdf

3. G.V. Esaulov, Urban planning doctrine of the Russian Federation (2014)

4. Russian State Standard SP 42.13330.2011

5. M M. M'Ikiugu, Procedia - Social and Behavioral Sciences, 68, 815-825 (2011)

6. J. Foster, H. Foster, A. Lowe, S. Winkelman, The Center for Clean Air Policy (2011).

7. J. Bay B. Ong, Tropical Sustainable Architecture: Social and Environmental Dimensions, 46-52 (2006)

8. N. Sanjay, P. Chand, Passive cooling techniques of buildings: Past and present - a review, ARISER, 4, 37-46 (2008)

9. S. Sergeev, S., Kirillova, T., Krasyuk, I.: Modelling of sustainable development of megacities under limited resources, E3S Web of Conferences, 91, 05007 (2019)

10. N.R Saenko, Prokhorova, V.V., Ilyina, O.V., Ivanova, E.V, International Journal of Applied Business and Economic Research, 15(11), 207-217 (2017)

11. Yu. S. Lebedev, Architectural bionics, (1990)

12. E.V. Kotlyarova, Yu.Y.Dvornikov, The principles of the urban architectural environment (2014)

13. V. Logvinov, From green building to nature-integrated architecture (2016)

14. H. Burton, C. Tsourou, Healthy Urban Planning (2006)

15. L.F Kazanskaya, Smirnova, O.M.: Supersulphated Cements with Technogenic Raw Materials. International Journal of Civil Engineering and Technology, 9(11), 30063012 (2018)

16. http://www.km.ru/referats/5B573044D72D4C02B09 164792B34D7A6

17. Lebedeva, T., Yakovlev, A., Kepp, N., Ikramov, R.: Possibilities and threats to TQM implementation in the innovation processes, IOP Conference Series: Materials Science and Engineering, 497(1),012132 (2019)

18. Nilova, L., Naumenko, N., Kalinina, I.: A study of the forms of bound water in bread and bakery products using differential thermal analysis, Agronomy Research, 15 (2), 1386-1398 (2017)

19. A. I. Giyasov, Yu. G. Barotov, Ecology of urban areas, 3, 90-97 (2018) 